\title{
A Pilot Study of Dynamic Assessment of Vocabulary in German for Bilingual Preschoolers in Switzerland
}

\author{
Ilektra Maragkaki (Corresponding author) \\ Faculty of Psychology and Educational Sciences, University of Geneva \\ Boulevard du Pont-d'Arve 40, CH-1205 Geneva, Switzerland \\ Tel: 41-22-379-8767_E-mail: Ilektra.Maragkaki@unige.ch \\ Marco G. P. Hessels \\ Faculty of Psychology and Educational Sciences, University of Geneva \\ Boulevard du Pont d'Arve, 40, CH-1205 Geneva, Switzerland \\ \& Optentia Research Focus Area, Vaal Triangle Campus, \\ North-West University, Vanderbijlpark, South Africa
}

Received: Dec. 3, 2016 Accepted: Dec. 22, 2016 Published: February 1, 2017

doi:10.5296/jse.v7i1.10392 URL: http://dx.doi.org/10.5296/jse.v7i1.10392

\begin{abstract}
The vocabulary subtest of the Dynamic Assessment of Preschoolers' Proficiency in Learning English (DAPPLE) was adapted in German and administered to 6 typically developing and 6 language-impaired bilingual preschoolers in Switzerland, as part of a short pilot project. The children were, also, assessed with a standardized test of vocabulary. Our aim was to determine whether the dynamic test would lead to a more accurate classification of the two groups (and their linguistic skills) than the standardized test. Overall, the findings confirm our initial question and are in line with the results of the DAPPLE study. This small-scale study may, therefore, be considered as a successful-initial-version of the vocabulary part of the DAPPLE in German. It, also, provides the basis for the creation of a more elaborate version of the DAPPLE battery and of a more comprehensive dynamic screening of bilingual children's ability to learn German. Future adaptations and improvements are discussed.
\end{abstract}

Keywords: Bilingualism, Dynamic Assessment, Language, German, Children 


\section{Introduction}

Static measures that examine children's prior knowledge in a particular domain may lead to incorrect diagnoses of primary language impairment (PLI); as a result culturally or linguistically diverse (CLD) preschoolers often are under-referred to special services, as any linguistic or literacy difficulties might be attributed to second language learning issues (Kapatzoglou, Restrepo, \& Thompson, 2012). On the other hand, as these children's limited performance may not reflect their true potential, this may lead to over-referral to special services. A child's limited performance on standardized language assessments may be caused by factors, such as diverse learning experiences or lack thereof, which is often the case with children from linguistically diverse backgrounds.

Dynamic Assessment (DA) is an alternative form of testing and is rooted in Vygotsky's theory of cognitive development (1986). Within this model, learning occurs through the social interaction with more experienced others in the so-called 'zone of proximal development', which is the distance between the current level of a child's achievement and the maximum level that can be reached with support from capable peers (Olswang \& Bain, 1996). Several methodologies have been developed over the last decades (Grigorenko \& Sternberg, 1998), but all share a common principle: the incorporation of an instructional interaction (mediation) within the assessment process in order to estimate in a qualitative way the potential (aptitude) of a child to learn regarding a specific task or domain. The most frequently used DA approaches include: a) Testing-the-limits, during which the "testing question" is modified in order to encourage children to show what they know, b) Graduated prompts, which entails the incorporation of verbal or other cues that are graduated from least to most assistive and c) Test-teach-retest, which include an intervention during the testing process, aimed to change the examinee's level of functioning (Guittierez-Clellen \& Pena, 2001).

Although Dynamic Assessment (DA) has been implemented as a culturally fair means of cognitive assessment for 50 years (e.g. Budoff \& Friedman, 1964, Campione \& Brown, 1987; Feuerstein, 1979; Hessels, 1996, 1997; Robinson-Zanartu \& Jensen, 1991), it was only relatively recent that language researchers and clinicians have recognized its potential for determining children's language learning potential (e.g. Camilleri \& Law, 2007; Guttierez-Clellen, Brown, Conboy, \& Robinson-Zanartu, 1998; Olswang \& Bain, 1996; Peña, Iglesias \& Lidz, 2001). DA has been used to reduce bias in the identification of language impairment (Pena, Quinn \& Iglesias, 1992), and to assess children's potential for language change (Olswang \& Bain, 1996). It has been successfully used to make prognosis and inform intervention in areas, such as phonology (Glaspey \& Stoel-Gammon, 2007), receptive vocabulary (Camilleri \& Law, 2007), as well as narrative ability, vocabulary, and discourse (Peña et al., 2006). Specifically, the ability of linguistically diverse children to learn new words has been thoroughly researched (Lidz \& Pena, 1996; Peña et al., 1992, 2001); the use of this specifically devised DA resulted in accurate differentiation between true language impairment and linguistic "difference" due to a multilingual context. 
Children's performance on DA tasks in areas such as word-learning suggest that when this information was combined with their post-test performance on a related static test, this resulted in more accurate classification of their learning ability in comparison to static tests alone (Pena, et al., 2001; Ukrainetz, Harpel, Wall, \& Koyle, 2000). Specifically, the findings of these studies suggest that with regards to predictive validity, a highly "modifiable" child, i.e. with a high DA score, which also exhibits gains at the static test between different time points, is more likely to have typical abilities compared to a child showing little change on DA and static measures (Hessels, 1997, 2002). This method of testing can, therefore, yield information that could not otherwise be obtained, lead to meaningful differentiations of high clinical and educational usefulness and improve the quality of the delivered intervention.

Further to these overall advantages, DA can be particularly useful, when screening Children with CLD, as it looks into the ability of the individual to learn new skills and does not focus on acquired knowledge. In other words, such a DA tool would be administered only in L2 (second language), without including the child's first language, as this would constitute "acquired knowledge". Such a procedure may contribute to a more economical use of the evaluation time. A promising example of a DA screening instrument was recently developed on such a basis in the UK by Hasson, Camilleri, Jones, Smith, \& Dodd, (2013). The Dynamic Assessment of Preschoolers' Proficiency in Learning English (DAPPLE), was successfully employed to identify differences in the responses of bilingual children who have been referred for speech and language intervention and bilingual children who are considered to be typically developing, within the context of the learning opportunities provided by DA. This protocol was adapted by these authors and will be, therefore, presented in more detail later. Finally, it is worth mentioning that DA is one of the recommended practices for bilingual assessment by organisations, such as the American Speech and Hearing Association (ASHA) and the International Association of Logopedics (IALP) (Caeser \& Kohler, 2007).

\section{Recommended practices regarding assessment of Children with CLD}

To appropriately assess the language capacities of Children with CLD, the ASHA (ASHA, 2004) has made a series of recommendations. Speech therapists need to obtain sufficient knowledge of the specific linguistic characteristics, as well as the sociolinguistic features of the child's significant cultural inferences and collaborate appropriately with interpreters to ensure the child is assessed in both language using all available resources (interpreters, interviews with parents, etc.) to understand what is considered typical vs disordered language patterns in the child's language and cultural community. They, also, need to be aware of current research and preferred practice in the identification/assessment of language disorders/delays, as well as of the relevant legal guidelines. Furthermore, they need to be able to distinguish a disorder from a difference by using the norms of the child's linguistic community as the standard and understand the standards of communicative competence in the child's communication environment. With regards to assessment, when appropriate, published test materials of language assessment, such as "standardized norm-referenced tests and criterion-referenced tests", should be used, taking into consideration the "general psychometric issues related to validity and reliability, and inherent cultural and linguistic biases in these test materials"(ASHA, 2004, p.4). When assessment materials/tests fail to 
meet such standards, they should be used informally, with no accompanying scores (such as in the case of translated tests). Finally, recommended alternative approaches to assessment include dynamic assessment, portfolio, interview and narrative assessment, structured observation, academic and social language sampling and curriculum-based procedures, including analysis of validity, reliability, and inherent cultural and linguistic biases (ASHA, 2004).

\section{Language assessment in the German-speaking cantons of Switzerland}

Switzerland has four official languages: German, French, Italian and Romansch. German is spoken by around $63 \%$ of the population, including both High-German and Swiss-German variations. Swiss-German is a dialectal variation of German, used frequently in oral speech and is characterized by different sub-variations that may differ from canton to canton, while High-German is used in most formal occasions, including the educational settings. Nearly $25 \%$ of the population residing in Switzerland, aged 0-19 years, have foreign citizenship (Bundesamt für Statistik, 2014). Language competence of children of foreign background has been found to be crucial for their educational success; according to the results of the Program for International Students Assessment (PISA), which compared the reading skills of migrant children at the end of obligatory education, the competencies of Swiss migrant students were among the lowest out of all the countries included in the study (BFS \&EDK, 2002). Although the policy regarding the support of language acquisition of CLD children has significantly changed since then, it still appears today that the educational circumstances and prospects for these children are far from ideal. In the canton of Zürich the representation of migrant children in the school system is as follows: while in some regions $30 \%$ of student population in special schools are of non-Swiss origin, this percentage drops down to only $25 \%$ of the students in primary, secondary and vocational schools and 10-15\% in high-school or university (Bossart \& Weidinger, 2011). This type of evidence, along with the ever-growing global migration, highlight the importance of bilingualism in the current educational and linguistic research in Switzerland.

With regards to speech and language therapy provision regarding CLD children in Switzerland, it appears that the multilingual linguistic tradition of the country is reflected in the increased number of bilingual therapists-as compared to Germany or Austria. Also, there is report of comparatively high percentages of collaboration with translators and involvement of parents during the assessment and therapeutic process, as mentioned in a recent study about practices of speech therapists concerning CLD children with (Schütte \& Lüdtke, 2013). In other words, the overall recommendations regarding sociolinguistic factors and involvement of relevant services seem to be met, at least to a degree.

However, when it comes to the actual assessment of CLD children with, the situation is less positive. Based on the same study (Schütte \& Lüdtke, 2013), the Swiss therapists obtained the lowest score on the item "Usage of known bilingual instruments", when compared to their German and Austrian colleagues. Furthermore, Häusermann (2009) acknowledges the difficulties met by local therapists to take into consideration the children's overall linguistic skills (in both languages), either because of a lack of knowledge of the children's first 
language or due to difficulty identifying and using a suitable instrument in German. The author highlights the methodological issues around employing norms of High-German tests and proposes the usage of a play-based assessment of non-verbal behavior, as a way to obtain clinically useful information. In addition, due to a lack of sufficient and valid assessment measures in Swiss-German in general (Hartmann, Rindlisbacher, Till, \& Winkes, 2015), it is not uncommon for many therapists to rely on personal adaptations of instruments in High-German (presented below) or on informal measures, i.e. unofficial adaptations of bilingual tests in Swiss-German exist. One exception appears to be a recent publication entitled "Sprachstandserfassung" (HfH Zurich) with specific guidelines on the optimal assessment procedure regarding bilingual children (Diagnostik der Sprachlichkeit bei Migrationshintergrund). The employment of a compilation of different parts of tests or procedures is recommended, such as the Communication Profile for Bilingualism (Kommunikatives Profil Mehrsprachigkeit für Kinder zwischen 3,5 und 5,5 Jahren; Ersoy, Juditzki, Mühling, Steiner, \& Tölken, 2003), Subtests of the Patholinguistic Diagnosis (Patholiguistischen Diagnostik bei Sprachentwicklungsstoerungen; Kauschke \& Siegmüller, 2002), questionnaires and clinical sampling techniques, such as the comparative measurement of the Mean Length of Utterance (MLU), which should be to assess children's performance in both home language and Swiss-German in the areas of pragmatics, semantics, morphology and phonetics. However, to our knowledge, no studies have been published confirming the usefulness of these recommendations within the specific context. Overall, it is argued that there is a lack of adequate speech and language assessment tools regarding the use of Swiss-German of CLD children (Häusermann, 2009).

\section{Instruments used in the Swiss-German context}

Some of the most commonly used formal assessment tools regarding the evaluation of linguistically diverse children by Swiss-German therapists are presented below. Reference to reliability or validity is provided only in the cases that such data is available.

Firstly, HAVAS-5-/Hamburger Verfahren zur Analyse des Sprachstandes bei Fünfjährigen (Analysis of the linguistic level of 5-year-olds), (Heitmann, Reich \& Roth, 2003) is a non-standardized assessment that looks into levels of receptive and expressive linguistic competence based on a 10-minute sample of a child's utterances in both languages, it offers a comparison of competence in both L1 and L2 (5-6 years old). It has an overall reliability of .63(Cronbach's alpha)."Kenntnisse in Deutsch als Zweitsprache: Screening modell für Schulanfänger" (Knowledge of German as a Second Language: Screening for school beginners; Staatsinstitut für Schulqualität und Bildungsforschung München, 2002), is a screening tool targeting children in reception year or Year 2 which is based on an interview of the child in German and comprises four different levels depending on competence. There is no data available regarding reliability.

A third instrument is the "Sprachstandsüberprüfung und Förderdiagnostik für Ausländerkinder"(Test of the linguistic level of foreign children; Hobusch, Lutz, \& Wiest, 1999), which is designed for children from 6- 10 years old. It is standardized but can, also, used informally to assess children's ability to answer questions, follow directions or describe 
pictures in German.There is no data available regarding reliability or validity. "Diagnostische Leitfragen"(Diagnostic questions; Knapp, 2001) is a questionnaire that evaluates teachers' observations of children's linguistic competencies in different areas.

Furthermore, "Linguistische Sprachstandserhebung - Deutsch als Zweitsprache Lise-Daz"(Linguistic evaluation-German as a Foreign Language; Schulz \& Tracy, 2012) is a comprehensive assessment of language for children between 3-8 years of age, which has been standardized using children with German as an additional language (GAL). This test has a high reliability: ICC:.92-.99. The "Cito-Sprachtest" (Language test) Version 3 (Cito Deutschland, 2010k) is a computer-based test examining passive vocabulary, cognitive concepts, phonological awareness, and text comprehension. Reliability regarding these subtests varies between .76- .91 (Cronbach's alpha).The Delfin-4/"Diagnostik, Elternarbeit, Förderung der Sprachkompetenz In Nordrhein-Westfalen bei 4-Jährigen"(Assessment, Parental support, and Stimulation of the linguistic competence of 4-year-olds), (Fried, Briedigkeit $\&$ Schunder, 2008) is a two-level procedure, which was devised to determine the school readiness of children between 4-7 years of age. Despite its good reliability (Level 1: .86, Level 2:.95), it has been criticized for its cultural appropriateness, as will be explained later.

Moreover, the SISMIC questionnaire / "Sprachverhalten und Interesse an Sprache bei Migrantenkindern im Kindergarten" (Linguistic behaviour and interest in language regarding migrant kindergarteners), (Ulich \& Mayr, 2004) provides a systematic basis for the observation of the linguistic development of migrant children from age 3.5 until around 6.Finally, with regards to the inductive approach (Induktive Ansatz), the focus is on the use of mobile phones by the parents as a way to obtain naturalistic samples of a child's speech in both languages of children from age 3 (Scharff-Rethfeld, 2014) .

Despite the usefulness of the above measures, their weaknesses should not be overlooked, especially when considering internationally accepted guidelines (ASHA, IALP) for recommended practices for bilingual assessment, such as i)using translators/interpreters to assess a child in both languages, ii) using alternative assessment procedures, such as DA and not rely on standardized tests, iii) using some formal standardized tests appropriately, as well as interviewing techniques (Caeser \& Kohler, 2007).

Within this context, questionnaires, such as SISMIC and Diagnostische Leitfragen, although informative, provide only partial information regarding a child's skills. Bilingual assessment should include some direct assessment tasks, formal or informal, administered by a speech therapist. Unless these tests are in the child's first language, the usage of any norms should be avoided or done with extreme caution (RCSLT, 2007). Furthermore, when testing children only in school-age, e.g. with the "Sprachstandsüberprüfung und Förderdiagnostik für Ausländer/kinder", the possibility for early detection of language disorder has passed and, thus, the opportunity for timely intervention. In addition, for all of the aforementioned tests, there is a lack of available information regarding their predictive or prognostic validity, as pointed out by a recent meta-analysis regarding the quality of existing assessment instruments (Neugerbauer \& Becker-Mrotzek, 2015). A further important issue concerns the proposed standardization of most previously mentioned tests. E.g., in the case of Delfin-4 the actual 
bilingual background of children has not been considered during the norming process. Therefore, this test serves as a standard criterion test of monolingual children (Settinieri, 2012). In the case of the CITO test, although it offers norms for children with Turkish as a second language, it is evident that these could not be used with children from different backgrounds, which may have an entirely different linguistic profile. In the case of Lise-Daz, it is not clear what the first language was of the children that were included in the reference norms. The issue of unavailability of reliable norms is further complicated when considering the case of children, who acquire German as a third language. Finally, where the "Inductive approach" is concerned, no published data exists on the reliability, efficiency or time needed for this process.

Based on the aforementioned information the following conclusions could be drawn:

a) Only very few tests have specifically been devised for children with German as a second language;

b) Existing tests do not cover the demands of all children, as they offer norms for specific language groups, if at all;

c) All of the aforementioned tests are static tests and, thus, have low prognostic value and do not offer any information on the children's potential for language learning, with the exception of some useful items in some questionnaires;

d) The lack of adaptations in Swiss-German further complicates assessment.

When considering the general recommendation to assess CLD Children in both their languages (IALP, 2006; ASHA 1985), one should point out the evident difficulty to implement this principle by monolingual therapists and the subsequent need for alternative methodologies. Dynamic assessment can, partially, overcome this practical problem, because, in addition to its predictive validity, it can offer valuable clinical information, as it does not focus on acquired knowledge alone. DA could provide an economical and reliable way to assess and, especially, screen for a child's needs, regardless of the exact linguistic circumstances and background, such as the number of home languages, the exact time of exposure to the language and so forth. In all respects, the fact that local therapists need to incorporate DA techniques into bilingual assessment has already been highlighted (Frigerio-Saiylir, 2013).

\section{Pilot study of the dynamic assessment of language}

As mentioned earlier, the DAPPLE (Hasson, Camilleri, Jones, Smith, \& Dodd, 2013) was developed to address the pressing issue of early identification of language impairment among bilingual children in the UK, who are often misdiagnosed (De Lamo White \& Jin, 2011). DAPPLE was conceived as a pre-diagnostic screening for the discrimination between language difference due to a bilingual background and true language/speech impairment and not as a fully validated diagnostic instrument. "If clear differences were found within the individual components and/or within the assessment as a whole, it would be feasible to further explore whether the DA can reliably be used to identify children at risk of language difficulties. Such an assessment could constitute a valuable decision-making tool for speech and language therapists working with bilingual children" (Hasson et al., 2013, p.62). The DAPPLE consisted 
of subtests of vocabulary, phonology, and expressive language. The differences found between the two groups are in support of the usefulness of such an assessment to identify bilingual children that are at-risk of language impairment. In particular, in all examined areas the caseload children required a greater amount of prompting during the dynamic phase than the control group. Regarding vocabulary, the authors conclude that the ability to retain new words may further differentiate children with lower scores and emphasize the need for a more sensitive DA.

A small scale pilot project was carried out in 2015 in order to explore the usefulness of a creation of a German version of the DAPPLE procedure in Switzerland. Due to the restricted nature of the study, it was decided to trial only one subtest of the battery, namely the vocabulary subtest. An abbreviated version of the methodology proposed by Camilleri \& Law (2007) was followed.

The main objective of the project was to examine whether the administration of a Dynamic Test of receptive vocabulary would provide better differentiation between groups of bilingual preschoolers with and without language difficulties compared to a static test of German vocabulary.

\section{Method}

\subsection{Sample}

Ethical approval was obtained by the Ethics Committee of the Department of Psychology and Educational Sciences of University of Geneva and parental consent was ensured. As this was a preliminary, pilot study, a sample of twelve children was considered sufficiently large to trial the adapted procedure. The children, aged 3 to 5 years and using German as 2 nd or 3 rd language, were allocated into two equal groups: a) children who had been referred to speech therapy services due to speech and language difficulties ("caseload") and b) children without any such difficulties. Following the example of the DAPPLE study, we adopted Mackey's definition for "bilingualism", which includes "individuals who use two or more languages in any modality, namely speaking, reading or writing" (as cited in Hasson, Camilleri, Jones, Smith, \& Dodd, 2013). Some of the children of the first group were identified as clients of private speech therapists through the Association of Swiss-German Speech Therapists (Deutschschweizer LogopädINnen Verband), while some others attended an educational setting for children with speech and language difficulties. The children of the second group attended a bilingual kindergarten. Following the DAPPLE methodology, children of both groups should have a minimal exposure of several months to High and/or Swiss-German daily. The data for the two groups' chronological age and linguistic background is shown in Table 1. Children for whom intellectual difficulties or hearing problems were reported by educators or therapists were excluded. 
Table 1. Sample characteristics

\begin{tabular}{|c|c|c|c|c|c|c|c|c|}
\hline & \multicolumn{2}{|c|}{$\begin{array}{l}\text { Age in } \\
\text { months }\end{array}$} & \multicolumn{6}{|c|}{ Additional/First Language } \\
\hline & $\mathrm{M}$ & SD & French & Spanish & Serbian & Albanian & Portuguese & English \\
\hline $\begin{array}{l}\text { Bilingual } \\
\text { caseload } \\
(n=6)\end{array}$ & 58.7 & 10.9 & 1 & & 1 & 3 & 1 & 1 \\
\hline $\begin{array}{l}\text { Bilingual } \\
\text { control } \\
(n=6)\end{array}$ & 43.7 & 8.1 & 4 & 1 & & & & \\
\hline
\end{tabular}

The children that received speech therapy had a mean age of 58.7 months and, apart from Swiss-German /High- German were exposed to French, Serbian, Albanian, Portuguese or Spanish. The control group that was matched on receptive vocabulary ability rather than age, had a mean age of 43.7 months and was, also, exposed to French and/ or Spanish, in addition to German (High- and/ or Swiss-German).

\subsection{Procedure}

As the static test of receptive vocabulary (British Picture Vocabulary Scale-BPVS, Dunn, Dunn, Whetton, \& Burley, 1997) that was used at the DAPPLE study (Hasson et al., 2013; Camilleri \&Law, 2007), has not been adapted in German, a test of similar format was chosen, namely the Subtest of Receptive vocabulary (Category: nouns) of the Patholinguistische Diagnostik bei Spachentwicklungstörungen (PDSS; Siegmüller \& Kauschke, 2013). The adopted procedure consisted of a pretest-(dynamic) mediation-posttest, following the example of the vocabulary subtest of DAPPLE. At first, an informal turn-taking game was used as an ice-breaker. Then, during the static phase of the test, all children were presented with the task and had to identify the correct word by selecting (pointing to) the correct picture out of 3-one target among two distractors. Based on their responses, children obtained a raw, "static" score (pre-test). Once six unknown items were identified, they were noted down to be used in the following "dynamic" phase in the form of a game (intervention phase): Pictures of the six unknown items were presented to the children among pictures of words, which they had identified during the static pre-test. Children were given the possibility of employing problem-solving skills in order to create a new word association through the following three levels of mediation: Context (independent identification), Language (implicit identification) and Language-Context (explicit identification). Based on the required assistance, they were given a dynamic score of 3,2 or 1, respectively (dynamic receptive score). It should be noted that the offered levels of mediation were highly scripted, following the graduated prompts approach. The mediation phase was followed by a first immediate Expressive test and a second Expressive retention test (Post-test) in the form of a game. If children failed to name some of the items, they were asked to identify them at a receptive level. However, as a measurement of children's performance in this area was not mentioned in the DAPPLE paper, these scores were not analysed in the results. Finally, a note on the administration of the test should be made: Scoring of the receptive test -both during the static phase and the dynamic phase- relied on 
recording of the items the children had pointed to and was, therefore, straightforward to carry out by one therapist. With regards to the expressive test, the one-word responses were audio-recorded to ensure the best possible transcription. Wherever possible, another speech therapist was used to transcribe the responses of the children but this was not the case for all children. Although during the DAPPLE study two speech-therapists were used, it should be borne in mind that the DAPPLE battery consists of additional expressive components that require longer responses and more detailed syntactic and phonetic analysis, which was not the case in our study.

\section{Results}

Analysis of the performance of the two groups at the different phases included the comparison of the dynamic mediation scores with the static (raw) scores, as well as the two expressive tasks (post-test). It should be noted that as static scores (T-scores) express norms related to monolingual children, only raw scores are being mentioned. Furthermore, as the pre- and the post-test were administered on the same day there was no need to 'control' for maturation effects in this way. Mann-Whitney U-tests were used to detect significant differences between the groups. No significant difference was found regarding the raw scores of the pre-test between the two groups (Mann-Whitney $U=9.00 ; p=.18$ ) despite an age difference between them (the 'caseload' children were a little older on average: Mann-Whitney $U=33.000 ; p$ $=.02$ ). Interestingly, apart from these similar raw scores, there was, also, a pattern of core six or seven items, which the children of both groups failed to identify during the pretest. Table 2 illustrates the mean age of each group, as well as the mean and range of their performance at the different vocabulary tasks.

Table 2. Mean, Standard deviation and range of performance on receptive vocabulary measure for "caseload" and control bilingual children

\begin{tabular}{lcccccc}
\hline & $\begin{array}{c}\text { Bilingual } \\
\text { caseload } \\
(\mathrm{n}=6)\end{array}$ & SD & Range & $\begin{array}{c}\text { Bilingual } \\
\text { control }(\mathrm{n}=6)\end{array}$ & SD & Range \\
\hline $\begin{array}{l}\text { Raw score } \\
\text { receptive }\end{array}$ & 11.1 & 1.1 & $10-13$ & 12 & 0 & $10-14$ \\
$\begin{array}{l}\text { Dynamic receptive } \\
\text { score }\end{array}$ & 2.1 & 0.3 & $0-3$ & 2.6 & 0.3 & $0-3$ \\
$\begin{array}{l}\text { First expressive } \\
\text { naming trial (\%) }\end{array}$ & 55 & 44 & $0-100$ & 44 & 13 & $33-67$ \\
$\begin{array}{l}\text { Second expressive } \\
\text { naming-retention } \\
\text { trial (\%) }\end{array}$ & 28 & 31 & $0-67$ & 50 & 23 & $17-83$ \\
\begin{tabular}{l} 
Maintenance (\%) \\
\hline
\end{tabular} & -27 & 23 & $-66-34$ & +6 & 25 & $-33-34$ \\
\hline
\end{tabular}

With regards to the required amount of mediation during the dynamic phase, the caseload group required significantly more assistance than the control group (Mann-Whitney $\mathrm{U}=4.500$; $\mathrm{p}=.013$, one-tailed). Both groups did not differ from each other at first expressive naming 
(Mann-Whitney $U=19.500 ; p=.82$ ). Right after the dynamic phase, the caseload group achieved 55\% and the control group 44\%. However, during the second naming task, the caseload group retained $22 \%$ fewer items than the control group. However, this difference is not significant (Mann-Whitney $U=10.000 ; p=.24$ ). Importantly, the maintenance from first to second expressive naming is significantly different between the two groups (Mann-Whitney U $=6.500 ; \mathrm{p}=.033$, one-tailed). This shows that, where expressive vocabulary is concerned, the bilingual controls retained the newly established representations more easily than the caseload children.

Concerning the predictive validity of both types of testing, moderate positive correlations (not significant due to the small sample size: $\mathrm{N}=6$ ) were found between the mediation scores and both post-test performances in the control group. More mediation occurred together with an improvement of naming ability. In the caseload group, however, the relationship was inversed. The more mediation the children needed, the harder they found it to retain and express the new vocabulary, showing greater difficulties to use the learning context.The fact that the bilingual control children retained the newly established representations for longer than the caseload children and that the latter needed more assistance and had more difficulties in learning the new words confirm the usefulness of the piloted procedure.

\section{Discussion and future perspectives}

Overall, the present data indicate that although both groups initially had similar receptive raw scores, their performance on the dynamic measure (mediation) was differentiated on the basis of the existence of a language disorder. This differentiation is in line with the findings of the DAPPLE study (Hasson et al., 2013) and further reinforces the idea that incorporating a short dynamic intervention during the assessment phase of bilingual children may provide a more accurate understanding of their linguistic skills, compared to static tests alone. Specifically, the fact that caseload children received a lower Dynamic Score than the control group indicates that they were not able to use the "dynamic" context to create new referents as efficiently as the control group. This is positive evidence regarding the usefulness of the dynamic procedure, which was proven to be more "sensitive" than the static test. This finding, therefore, confirms at a first level our initial, overarching question.

Also, although non-significant in this very small pilot study, a difference seems to emerge regarding the amount of retained information at an expressive level, as measured by the post-test. The fact that the caseload children initially obtained higher scores on the immediate expressive naming task shows that they responded well to the dynamic (mediation) task. However, children's scores on the second task show that they were not able to retain this new information and use it expressively once a few minutes had passed. This result is indicative of the type of learning difficulty children of this profile might face within real learning environments. From a theoretical perspective, these overall findings tie in with results of studies, which have demonstrated the difficulty of language-impaired children to create new referents ("fast-map"), as well as accurate phonological and semantic representations of novel words during controlled studies of quick incidental learning (QUIL) (Dollaghan, 1987; Ellis-Weismer et al., 1999; Gray et al., 2004; Oetting et al., 1994). 
Due to the time and procedural restraints of the study there are a few limitations, such as the sample size and the chronological difference between the groups. Concretely, a larger sample could reveal whether differences are indeed statistically significant, for example, regarding children's ability to retain new information. Furthermore, testing of verbs should be added. In addition, a choice of a static test of receptive vocabulary with more refined norming groups, such as the Cito-Sprachtest Version 3 (Cito Deutschland $\mathrm{GmbH}$ ), would enable better comparisons. Also, additional time and resources would enable the administration of some form of testing of non-verbal cognitive abilities during the sampling process, as well as the inclusion of a second rater to ensure better reliability-especially in the case of inclusion of the expressive morphology and phonological subtests, respectively. Finally, with regards to receptive vocabulary, the inclusion of an immediate recall task during the intervention phase and of a delayed recall task during the post-test phase, as proposed by Camilleri (Camilleri \& Law, 2007), could be used to yield potentially better indices of predictive validity.

Presently, a larger study involving the aforementioned improvements, as well as a more elaborate dynamic assessment procedure is planned, thus constituting the basis for the first DA screening of this kind in Switzerland. The present pilot study shows that this seems a feasible approach in the Swiss context. Further analyses and comparisons with other procedures, such as the Lise-Daz, as well as non-word repetition tasks, could be used to further validate this process. Nonword repetition tasks have been shown to provide non-biased differentiation based on language ability of CLD children (Campbell et al., 1997). In addition, the incorporation of a parental questionnaire looking at the linguistic competencies of children's first language, such as the Alberta Language and Development Questionnaire (Paradis, Emmerzael, \& Sorenson Duncan, 2010) might provide additional valuable information to a future screening, as such reports have been found to be of high diagnostic accuracy when compared to other measures of language of bilingual children (Restreppo, 1998).

In conclusion, as mentioned earlier, there is a documented lack of valid instruments for assessing CLD children in Switzerland (Häusermann, 2009; Frigerio-Sayilir, 2013). In addition to this shortage of instruments, speech therapists in the wider German-speaking area (including Germany, Austria, and Switzerland) are reported to have low levels of knowledge of the existing bilingual assessment instruments (Schütte \& Lüdtke, 2013). Furthermore, dynamic assessment has proven to be a valid alternative method of testing such populations and, as such, it constitutes part of the international recommendations on best practices regarding the diagnosis of CLD children (ASHA, 2004; RCLST, 2007). The development and trialing of a screening on the basis of the DAPPLE example would, therefore, be a useful attempt to validate and incorporate dynamic procedures within the speech therapy assessment of CLD children in Switzerland. A successfully trialed screening could be part of early intervention schemes and integration frameworks, such as the "Frühe Förderung-Kantonale Integrationsprogramme "(Factsheet KIP 2014-2017; www.sem.admin.ch). The present pilot study provides some useful initial information that confirm the usefulness of the incorporation of dynamic testing during the language assessment procedure of children, for whom German is not the first or main language. The fact that within the multilingual context of Switzerland a non-negligible number of CLD children might not receive the quality of culturally-appropriate 
diagnostic services that they are entitled to, renders the investment into DA-related research, which has proven to be useful for this specific population, almost indispensable.

\section{References}

American Speech-Language-Hearing Association (2004). Knowledge and skills needed by speech-language pathologists and audiologists to provide culturally and linguistically appropriate services [Knowledge and Skills]. Available from http://www.commxroads.com/ docs/publications/Knowledge_Skills.pdf

Alt, M., Plante, E., \& Creusere, M. (2004). Semantic features in fast-mapping: Performance of preschoolers with specific language impairment versus preschoolers with normal language. Journal of Speech, Language, and Hearing Research, 47, 407-420. http://doi.org/10.1044/1092-4388(2004/033)

Bossart M.N. \& Weidinger W. (2011). Zur Integration mehrsprachiger Schülerinnen und Schüler unter besonderen Umstäenden[Towards the integration of multilingual children in particular situations]. Erziehung und Unterricht, 1(2), 1-10.

Budoff, M., \& Friedman, M. (1964). "Learning Potential" as an assessment approach to the adolescent mentally retarded. Journal of Consulting Psychology, 28(5), 434-439. http://doi.org/10.1037/h0040631

Bundesamt für Statistik \& Schweizerische Konferenz der kantonalen Erziehungsdirektoren (2002). Für das Leben gerüstet? Die Grundkompetenzen der Jugendlichen -Nationaler Bericht der Erhebung PISA 2000.Neuchâtel: Bundesamt für Statistik.

Bundesamft für Statistik (2014). Demographishes Porträt der Schweiz. https://www.bfs.admin.ch/bfs/de/home/statistiken/bevoelkerung/stand-entwicklung.assetdetai 1.346792.html;https://www.bfs.admin.ch/bfsstatic/dam/assets/349846/master

Caesar L. \& Kohler P. (2007). The state of bilingual school-based bilingual assessment: actual practice versus recommended guidelines. Language, Speech, and Hearing Services in Schools, 38(3), 190-201. http://doi.org/ 10.1044/0161-1461(2007/020)

Caffrey E., Fuchs L., \& Fuchs D. (2008). The predictive validity of dynamic assessment: A Review. Journal of Special Education, 41(4), 254-270. http://doi.org/ 10.1044/0161-1461(2007/020)

Camilleri, B., \& Law, J. (2007). Assessing children referred to speech and language therapy: Static and dynamic assessment of receptive vocabulary. International Journal of Speech-Language Pathology, 9(4), 312-322. http://dx.doi.org/10.1080/14417040701624474

Campione, J.C., \& Brown, A.L. (1987). Linking dynamic assessment with school achievement.In Lidz, C.S. (ed.) Dynamic Assessment: An Interactional Approach to Evaluating Learning Potential (pp. 82-115). New York: Guilford Press.

CITO Deutschland Datenblatt (2013), Cito-Sprachtest Version 3. Solingen: Cito Deutschland $\mathrm{GmbH}$. 
Conti-Ramsden G., \& Hesketh A. (2003). Risk markers for SLI: a study of young language-learning children. International Journal of Language \& Communication Disorders, 38(3), 251-263. http://dx.doi.org/ 10.1080/1368282031000092339

De Lamo White, C., \& Jin, L. (2011). Evaluation of speech and language assessment approaches with bilingual children. International Journal of Language \& Communication Disorders, 46(6), 613-27. http://doi.org/10.1111/j.1460-6984.2011.00049.x

Dollaghan C. (1987). Fast mapping in normal and language-impaired children. Journal of Speech and Hearing Disorders, 52, 218-222. http://dx.doi.org/ 10.1044/jshd.5203.218

Dunn, L., Dunn, L., Whetton, C., \& Burley, J. (1997). The British Picture Vocabulary Scale. Windsor: NFER-Nelson.

Ellis-Weismer, S., Evans, J., \& Hesketh, L. J. (1999). An examination of verbal working memory capacity in children with specific language impairment. Journal of Speech,Language and Hearing Research, 42, 1249-1260. http://dx.doi.org /10.1044/jslhr.4205.1249

Ersoy, D.,Juditzki, B., Mühling, C., Steiner, J., \& Tölken, J. (2003).Praktische Aspekte der Diagnostik in Arbeitsfeld Mehrsprachigkeit: Das Monheimer Modell [Practical aspects of diagnosis in multilingual context:the Monheimer model]. Die Sprachheilarbeit, 48, 5, 184-193.

Feuerstein, R.(1980). Instrumental enrichment:An intervention program for cognitive modifiability Baltimore, MD: University Park Press.

Fried L., Briedigkeit. E., Schunder R. (2008). Dürchuführungsanleitung zur Stufe 1:Besuch im Zoo(BiZ)[Introduction to administration for the first grade: a visit to the zoo].Begleitheft zu :Delfin 4.Diagnostik, Elternarbeit und Förderung der Sprachkompetenzen Vierjähriger in $N R W$.Dortmund:Technische Universität Dortmund

Frigerio-Sayilir C. (2013). Mehrsprachige Kinder im logopädischen Alltag [Multilingual children in speech therapy practice]. DLV Aktuell 4, 2013

Glaspey, A., \& Stoel-Gammon, C. (2007). A Dynamic approach to phonological assessment. Advances in Speech Language Pathology, 9, 286-296. http://dx.doi.org/10.1080/14417040701435418

Gray S. (2003). Diagnostic accuracy and test-retest reliability of nonword repetition and digit span tasks administered to preschool children with specific language impairment. Journal of Communication Disorders, 36, 129-151. http:/ovidsp.ovid.com/ovidweb.cgi?T=JS\&PAGE= reference $\& D=$ emed6\&NEWS $=\mathrm{N} \& A N=2003103012$

Gray, S. (2004). Word learning by preschoolers with Specific Language Impairment. Journal of Speech Language Hearing Research, 47(5), http://dx.doi.org/1117.10.1044/1092-4388(2004/083)

Grigorenko, E.L, \& Sternberg, RJ. (1998). Dynamic testing. Psychological Bulletin, 124(1), 75-111. http://dx.doi.org/ 10.1037/0033-2909.124.1.75 
Grimm, H. \& Schöler, H. (1999). HSET, Heidelberdeger Sprachentwicklungstest [Heidelberg Test of Language Evaluation]. Goettingen:Hoegrefe.

Grüningen, R.,Perren, S., Nägele, C., \& Alsaker, F. (2010). Immigrant children's peer acceptance and victimization in the kindergarten: The role of local language competence. British Journal of Developmental Psychology. http://dx.doi.org/ 10.1348/026151009X470582

Gutierrez-Clellen, V. F., Brown, S., Conboy, B., \& Robinson-Zanartu, C. (1998). Modifiability: A dynamic approach to assessing immediate language change. Journal of Children's Communication Development, 19(2), 31-42. http://dx.doi.org/10.1177/152574019801900204

Hartmann E., Rindlisbacher B., Till C \& Winkes J.,(2015).Entwicklung und Diagnostik des Sprachverständnisses bei Deutschschweizer Kindern [Development and evaluation of language]. Vierteljahresschrift für Heilpädagogik und ihre Nachbargebiete (VHN), 84, 167-169.

Hasson, N., Dodd, B., \& Botting, N. (2012). Dynamic Assessment of Sentence Structure (DASS): design and evaluation of a novel procedure for the assessment of syntax in children with language impairments. International Journal of Language \& Communication Disorders, 47, 285-299. http://dx.doi.org/10.1111/j.1460-6984.2011.00108.x

Hasson, N., Camilleri, B., Jones, C., Smith, J., \& Dodd, B. (2013). Discriminating disorder from difference using dynamic assessment with bilingual children. Child Language Teaching and Therapy, 29(1), 57-75. http://dx.doi.org/10.1177/0265659012459526

Häuser, D., Kasielke, E., \& Scheidereiter, U. (1994). KISTE. Kindersprachtest für das Vorschulalter [Test of child language in preschool age]. Weinheim:Beltz.

Häusermann, J. (2009). Der Deutscherwerb von Vorschulkindern mit Migrationshindergrund [The acquisition of German by preschoolers of migrant background]. Forum Logopaedie, 23(3), 16-21.

Hessels, M.G.P. (1997). Low IQ but high learning potential: Why Zeyneb and Moussa do not belong in special education. Educational and Child Psychology, 14, 121-136.

Hessels, M.G.P., \& Hessels-Schlatter, C. (2002). Learning potential in immigrant children in two countries: The Dutch and the Swiss-French version of the Learning Potential Test for Ethnic Minorities. In D.G.M. van der Aalsvoort, W.C.M. Resing, \& A.J.J.M. Ruijssenaars (Eds.), Learning potential assessment and cognitive training. Actual research and perspectives in theory building and methodology (pp. 227-245). Oxford: Elsevier.

Kapantzoglou, M., Restrepo, M.A., \& Thompson, M.S. (2011). Dynamic assessment of word learning skills: Identifying Language Impairment in Bilingual Children. Language, Speech and Hearing Services in Schools, 43, 81-96. http://dx.doi.org/10.1044/0161-1461(2011/10-0095)

Kauschke C., \& Siegmüller.J. (2002). Patholinguistische Diagnostik bei Sprachentwicklungsstörungen [Patholinguistic evaluation of developmental language disorder]. Uban \& Fischer, 
München.

Lidz, C.S., \& Peña, E.D. (1996). Dynamic assessment: The model, its relevance as a non-biased approach and its application to Latino American preschool children. Language, Speech, and Hearing Services in Schools, 27, 367-372. http://dx.doi.org/10.1044/0161-1461.2704.367

Neugebauer,U., \& Becker-Mrotzek, M. (2015). Gütemerkmale von 21 Sprachstandsverfahren im Elementarbereich [Language evaluation procedures in the kindrgarten].In Esse G., Hasselhorn M., Schneider W.(Eds.), Diagnostik im Vorschulalter (pp.19-42). Göttingen: Hogrefe.

Oetting, J.B. Rice, M.L., \& Swank. L.K. (1995). Quick incidental learning (QUIL) of word learning in school-age children with and without SLI. Journal of Speech and Hearing Research, 38, 434-445. http://dx.doi.org/10.1044/jshr.3802.434

Olswang, L.B., \& Bain B.A. (1996). Assessment information for predicting upcoming change in language production. Journal of Speech and Hearing Research, 39, 414-423. http://dx.doi.org/10.1044/jshr.3902.414

Paradis, J., Emmerzael, K., \& Sorenson Duncan, T. (2010). Assessment of English language learners: Using parent report on First Language Development. Journal of Communication Disorders, 43, 474-497. http://dx.doi.org/10.1016/j.jcomdis.2010.01.002

Peña, E., Gillam, R., Malek, M., Ruiz-Felter, R., Resendiz, M., Fiestas, C., \& Sabel, T. (2006). Dynamic assessment of children from culturally diverse backgrounds: Applications to narrative assessment. Journal of Speech, Language, Hearing Research, 49, 1-21. http://dx.doi.org/10.1044/1092-4388(2006/074)

Pena, E.D., Iglesias, A., \& Lidz, C.S. (2001). Reducing test bias through dynamic assessment of children's world learning ability. American Journal of Speech-Language Pathology, 10, 138-154. http://dx.doi.org/ 10.1044/1058-0360(2001/014)

Peña E., Quinn, R., \& Iglesias, A. (1992). The application of dynamic methods to language assessment: A nonbiased procedure. Journal of Special Education, 26, 269-280. http://dx.doi.org/ 10.1177/002246699202600304

Reich, H., \& Roth, H. (2004). HAVAS 5. Hamburger Verfahren zur Analyse des Sprachstandes bei 5-jaehrigen [Hamburger instrument for the analysis of the language level of 5-year olds]. Hamburg: Behörde für Bildung und Sport.

Restrepo, M. A. (1998). Identifiers of predominantly Spanish-speaking children with language impairment. Journal of Speech, Language, and Hearing Research, 41(6), 1398-1411. http://dx.doi.org/10.1044/jslhr.4106.1398

Rethfeldt-Scharff W. (2014). Der Induktive Ansatz in der logopädischen Diagnostik und Therapie bei mehrsrpachigen Kindern [The inductive appoach for language asssessment and therapy with multilingual children].Sprachförderung und Sprachtherapie in Schule und Praxis, 3, 1, 23-30. 
Robinson-Zañartu, C., \& Jensen, M. R. (1991, October). Schools restructured to mediate learning: the social science and politics of classroom change. Paper presented to the California Association for Mediated Learning. Thousand Oaks, California.

Royal College of Speech, \& Language Therapists. (2007). Good Practice for Speech and Language Therapists Working with Clients from Linguistic Minority Communities. London: RCSLT.

Schulz. P., \& Tracy R. (2012). Manual. In G. Esser, M. Hasselhorn, \& W. Schneider (Eds.) Lise-DaZ. Linguistische Sprachstandserhebung - Deutsch als Zweitsprache [Language evaluation - German as second language]. Göttignen: Hogrefe.

Schütte, U., \& Lüdtke, U. (2013): Sprachtherapeutische Praxis im Kontext kindlicher Mehrsprachigkeit - Eine international vergleichende Bestandsaufnahme in Deutschland, Österreich und der Schweiz [Speech therapy practice in the context of childhood multilingualism-An international comparative survey in Germany, Austria and Switzerland]. Forschung Sprache 1(2), 45-60. http://dx.doi.org/10.2443/skv-s-2013-57020130204

Settinieri J. (2012). Möglichkeiten und Grenzen der Prüfung konvergenter Validität sprachstanddiagnosticher Verfahren [Opportunities and barriers of the evaluation of the convergent validity of diagnostic language instruments]. In Ahrenholz B. Einblicke in die Zweitspracherwerbsforschung und ihre methodischen Verfahren (pp 325-341). Berlin: Walter de Gruyter.

Sprachstanderfassung[Language level screening]. Electronic resource of the Interkantonale Hochschule für Heilpädagogik Zürich. Retrieved from: http://www.logopaedieundpraevention-hfh.ch/webautor-data/29/Sprachstandserfassung.pdf

Staatsinstitut für Schulqualität und Bildungsforschung München (2002): Kenntnisse in Deutsch als Zweitsprache erfassen. Screening-Modell für Schulanfänger [Detection of knowledge of German as a second language]. Stuttgart: Klett.

Ulich, M., \& Mayr.T. (2004). SISMIK:Sprachverhalten und Interesse an Sprache bei Migrantenkindern in Kindertageseinrichtungen. Begleitheft zum Boebachtungsbogen. [Language behaviour and interest in language among migrant children in preschool settings.Accompanying booklet to the observation form]. Freiburg im Breisgau: Herder.

Ukrainetz T., Harpell S., Walsh C., \& Coyle C. (2000). A preliminary investigation of dynamic assessment with native American kindergartens. Language, Speech and Hearing Services in Schools, 31, 142-154. http://dx.doi.org/10.1044/0161-1461.3102.142

Vygotsky L.S. (1986). Thought and Language. Cambridge, MA: MIT Press.

Zollinger B. (1997). Die Entdeckung der Sprache. Bern:Haupt.

\section{Copyright Disclaimer}

Copyright for this article is retained by the author(s), with first publication rights granted to the journal. 
This is an open-access article distributed under the terms and conditions of the Creative Commons Attribution license (http://creativecommons.org/licenses/by/3.0/). 